\title{
Research on Economic Synergistic Development in Domestic Ethnic Regions on "New Silk Road Economic Belt"
}

\author{
Haiying Ma \\ School of Economics, Northwest University for Nationalities Lanzhou (730124), P.R.China, \\ Ixmahaiying8888@163.com
}

Keywords: New Silk Road Economic Belt; Ethnic regions; Synergistic development

\begin{abstract}
This paper uses nine domestic ethnic regions long the "New Silk Road economic belt" as the research object, selects the appropriate order parameter and builds synergistic degree of complex system model to test the economic order of the nine regions and synergies of 2001 to2014. It turns out that ordering degree of regional economic subsystem radiate upward trend, indicating that the overall development of regional economy are not highly collaborative. What's more, the synergistic degree emerges fluctuated trend. Therefore, we should enhance cooperation, through the improvement of inter- regional institution-building and mechanisms to provide technical, financial support to achieve synergistic development of economy-related provinces.
\end{abstract}

\section{Introduction}

The "New silk road economic belt" is to inherit and carry forward the ancient Silk Road, and the deepening of the western development strategy and upgrade. as regional cooperation mode innovation, it aims to break the regional administrative monopoly, strengthen inter-regional cooperation. "New silk road economic belt" domestic northwest ethnic regions including Shaanxi, Gansu, Qinghai, Ningxia, Xinjiang, Chongqing, Guangxi, Yunnan, these areas are rich in natural resources, vast territory, is expected to become the "new silk road economic belt" hinterland of the gold. As an economic national strategy under the new normal, the "the new silk road economic belt" aims to promote the western inland areas form a new open front and economic growth pole.

From the Angle of synergetic to find solutions of the regional economic development though is still in its primary stage, but has drawn the attention of academic circles, scholars mainly study from two aspects: one is try to take advantage of coordinated regional economic development theory to solve the problem, $\mathrm{Li}$ (2005) defines the connotation of the coordinated development of regional economy, Zhi (2007) explored the driving mechanism of the coordinated development of regional economy. Li (2008) to build an index system of regional economic development. it is to use econometric method to build model for empirical research to measure the degree of coordination between different systems within the same area, Wei and Zhao (2015) of north China pharmaceutical industry's competitiveness evaluation research. This paper will be in different development status of national regional economic system as a subsystem, they form the system is called composite system, on the basis of the construction of regional economic coordination degree of compound system measure model, the "new silk road" determination of domestic section of the level of coordinated development of national regions, to reveal the "new silk road economic belt" coordinated development trend and highlight problems, and draw policy implications, different to the "new silk road economic belt" regional economic coordinated development has the vital significance of the system.

\section{Construction Model for Ethnic Regional Economic Coordination}

Subsystem Degree Model of Regional Economics. According to positive synergy theory, regional subsystems orderly degree measure model is divided into two steps. The first step is to measure the regional economic degree of order of the order parameter subsystem components. Order parameter is 
one of the important concept of synergetic is used to depict the system running state, the change of the order parameter direction controlling system changes direction, the orderly change will guide system from disorder to order. Set up regional economic subsystem $l_{j}(j \subset(1, n])$ in the process of development of order parameter for $l_{j i}=\left(j_{1}, j_{2} \cdots j_{m}\right)$. the greater the degree of orderly economic subsystem $l_{j}$ is higher; When $l_{j i}=\left(L J K j_{K}+2+1,1, \cdots, 1 j_{m}\right)$ as negative index, its value is smaller, the orderly degree of economic subsystem $l_{j}$ more high, the regional economic subsystem $l_{j}$ sequence parametric component $l_{j i}$ system orderly degree measure model is as follows:

$$
u_{j}\left(l_{j i}\right)=\left(\begin{array}{l}
\left(l_{j i}-\beta_{j i}\right)\left(\alpha_{j i}-\beta_{j i}\right)^{-1}, i=[1, k] \\
\left(\alpha_{j i}-l_{j i}\right)\left(\alpha_{j i}-\beta_{j i}\right)^{-1}, i=[k+1, m]
\end{array}\right.
$$

$U_{J}\left(l_{j i}\right)$ Said regional economic order parameter subsystem component $l_{j i}$ system orderly, $U_{J}\left(l_{j i}\right) \subset(0,1]$, the value will be greater the $l_{j i}$ contribution to $l_{j}$ orderly degree of regional economic subsystem is big. Alpha $l_{j}$ beta $l_{j}$ is the first regional economic $\mathrm{j}$ subsystems in the ith index's upper limit and lower limit, according to the ith indicators to determine the maximum and minimum possible growth, in this paper using the data in 2014 and 2001 as indicators of the upper and lower.

The second step is to measure the regional economic subsystem of the degree of order. Order parameter component in order to well reflect the $l_{j i} L_{j}$ orderly degree of regional economic subsystem of total contribution, need through the $U_{J}\left(l_{j i}\right)$ for integration, and the result of the integration with each component of the system not only the size of the degree of order value. This paper is integrated with the linear weighted summation method. After the integration of regional economic subsystem model for order:

The first step is calculating to establish regional economic subsystem $L_{j}$ m order parameter of the correlation coefficient matrix.

$$
L_{j i}=\left(\begin{array}{ccc}
l_{11} & l_{12} & l_{13} \\
l_{21} & l_{22} & l_{23} \\
\ldots & \ldots & \ldots \\
l_{31} & l_{32} & l_{33}
\end{array}\right) \quad L_{j i}=\left[\begin{array}{cccc}
l_{11} & l_{12} & \ldots & l_{1 m} \\
l_{21} & l_{22} & \ldots & l_{2 m} \\
\vdots & \vdots & & \vdots \\
l_{n i} & l_{n 2} & \ldots & l_{n m}
\end{array}\right] \quad l_{i}=\sum_{j=1}^{n}|l j i|-1, \lambda_{i}=\frac{l_{i}}{\sum_{i=1}^{m} l_{i}}
$$

The second step, by (1) the normalized processing each order parameter can be got the weight coefficient of lambda. $L_{i}$ said the I order parameter $L_{i}$.I indicators show that the first impact on the rest of the indicators, the greater the corresponding weights.

$$
\bar{u}_{i}\left(l_{j}\right)=\sum_{i=1}^{m} \lambda_{i} u_{j}\left(l_{j i}\right), \lambda_{i} \geq 0, \sum_{i=1}^{m} \lambda_{i}=1
$$

It shows that $u-j \subset j\left(l_{j}\right)$ the greater the show that $\mathrm{lj}$ impact on regional economic subsystem $l_{i}$ and orderly, the greater the degree of orderly regional economic subsystem, the opposite is lower. Lambda I as the weight coefficient, on behalf of $U_{J}\left(l_{j i}\right)$ in maintaining the process the role of the system can work properly. To determine the index weight of a variety of methods, this paper adopts the method of two-step correlation matrix determine the index weight.

Complex System Coordination Degree Model. Complex system coordination degree model is on the basis of the orderly degree of regional economic subsystem structure, used to further measure and judge the effect of compound system coordinated operation, its computation formula is as follows: 


$$
x=\theta \sqrt[n]{\left|\coprod_{j=1}^{n} \overline{u_{j}^{1}}\left(l_{j}\right)-\overline{u_{j}^{0}}\left(l_{j}\right)\right|},
$$

$$
\theta=\left\{\begin{array}{l}
\left.1,\left[\overline{u_{j}^{1}}\left(l_{j}\right)-\overline{u_{j}^{0}}\left(l_{j}\right)\right\rangle 0\right] \\
\vdots \\
-1
\end{array}\right.
$$

For complex system coordination degree model shows that: (1) model to reflect the regional economic subsystem $t 0$ from moment to moment $t 1$, its economy orderly degree $\mathrm{u}$ from its evolution to the $-u j_{i}$ (1) when the compound system on the synergy degree. (2) $x \subset[0,1]$, its value, the greater the composite system coordinated development degree is higher, the opposite is lower. (3) the meaning of the parameters theta is, if and only if the $u-j \subset j\left(l_{j}\right)>0$, composite system on the synergy degree is positive.

\section{Empirical Analysis}

The Selection of Order Parameter Indicators and Data Sources. Order parameter is exist in the internal system of macro variables, dominate the evolution trend of the system, is the coordinated movement of the characterization and measurement system. Therefore, selecting rational order parameter subsystem of regional economy, accurate measurement of the synergy degree has played a vital role. Regional economic coordination and process management subsystem commitment together will promote the regional economy coordination in output. economic benefits and income from three aspects of eight indicators to examine "the new silk road economic belt along the" nine provinces economy subsystem degree of order and the composite system on the synergy degree, index system are as Level of economic development(Per capita GDP (X1) and The whole society fixed asset investment (X2)); The economic structure(The added value of agriculture (X3), Industrial output (X4), The added value of the third industry (X5)); Economic benefits(Local fiscal revenue (X6), Urban per capita disposable income (X7), Per capita net income of rural residents (X 8)).

Data Processing. In order to eliminate the influence of different dimensional data, need eight to nine provinces order parameter of original data to standardize processing, because of the huge amount of data, the paper structure, so in the schedule reflect (because of the huge data volume, the schedule is abbreviated).

\section{Measurements Of Regional Economic Subsystem.}

1. The regional economic order degree of order parameter. The standardized data generation of order parameter of the regional economy degree of order and the weights:

Table 1 provincial weights of order parameter

\begin{tabular}{|c|c|c|c|c|c|c|c|c|}
\hline regions & $\begin{array}{c}\text { GDP } \\
\text { per } \\
\text { capita }\end{array}$ & $\begin{array}{c}\text { fixed } \\
\text { asset } \\
\text { investment }\end{array}$ & $\begin{array}{c}\text { added } \\
\text { value } \\
\text { agriculture }\end{array}$ & $\begin{array}{c}\text { added } \\
\text { value } \\
\text { industria } \\
1\end{array}$ & $\begin{array}{c}\text { added } \\
\text { value } \\
\text { tertiary } \\
\text { industry }\end{array}$ & $\begin{array}{c}\text { Local } \\
\text { fiscal } \\
\text { revenu }\end{array}$ & $\begin{array}{c}\text { Urban per } \\
\text { capita } \\
\text { disposable } \\
\text { income }\end{array}$ & $\begin{array}{c}\text { Per capita } \\
\text { net income } \\
\text { rural } \\
\text { residents }\end{array}$ \\
\hline Shanxi & 0.126 & 0.125 & 0.125 & 0.125 & 0.125 & 0.124 & 0.125 & 0.125 \\
\hline Gansu & 0.126 & 0.124 & 0.126 & 0.123 & 0.126 & 0.125 & 0.125 & 0.126 \\
\hline Qinghai & 0.129 & 0.126 & 0.128 & 0.126 & 0.129 & 0.126 & 0.128 & 0.129 \\
\hline Ningxia & 0.126 & 0.125 & 0.126 & 0.125 & 0.125 & 0.123 & 0.125 & 0.126 \\
\hline Xinjiang & 0.126 & 0.125 & 0.125 & 0.121 & 0.126 & 0.125 & 0.126 & 0.126 \\
\hline Chongqin & 0.126 & 0.126 & 0.125 & 0.122 & 0.124 & 0.124 & 0.126 & 0.125 \\
\hline Sichuang & 0.126 & 0.124 & 0.124 & 0.125 & 0.126 & 0.125 & 0.126 & 0.126 \\
\hline Yunnan & 0.125 & 0.125 & 0.125 & 0.124 & 0.125 & 0.125 & 0.125 & 0.125 \\
\hline Guangxi & 0.125 & 0.125 & 0.124 & 0.125 & 0.126 & 0.125 & 0.125 & 0.125 \\
\hline
\end{tabular}

2. The degree of order will be calculated the regional economic subsystem of nine regional economic order degree of order parameter and index weight substitution into (2) to calculate the orderly degree of regional economic subsystem as in Table 2. 
Table 2 provincial economic subsystem of the degree of order

\begin{tabular}{|c|c|c|c|c|c|c|c|c|c|}
\hline years & SX & GS & QH & NX & XJ & CQ & SC & YN & GX \\
\hline 2002 & 0.123 & 0.153 & 0.153 & 0.153 & 0.123 & 0.153 & 0.153 & 0.153 & 0.153 \\
\hline 2003 & 0.134 & 0.234 & 0.134 & 0.253 & 0.134 & 0.253 & 0.134 & 0.234 & 0.153 \\
\hline 2004 & 0.532 & 0.332 & 0.232 & 0.232 & 0.532 & 0.232 & 0.232 & 0.332 & 0.232 \\
\hline 2005 & 0.012 & 0.312 & 0.312 & 0.412 & 0.012 & 0.412 & 0.312 & 0.312 & 0.312 \\
\hline 2006 & 0.232 & 0.232 & 0.332 & 0.442 & 0.32 & 0.442 & 0.432 & 0.232 & 0.442 \\
\hline 2007 & 0.243 & 0.243 & 0.243 & 0.543 & 0.243 & 0.543 & 0.443 & 0.243 & 0.543 \\
\hline 2008 & 0.412 & 0.512 & 0.512 & 0.782 & 0.412 & 0.782 & 0.592 & 0.512 & 0.612 \\
\hline 2009 & 0.428 & 0.528 & 0.628 & 0.628 & 0.428 & 0.628 & 0.628 & 0.528 & 0.628 \\
\hline 2010 & 0.231 & 0.831 & 0.831 & 0.837 & 0.231 & 0.837 & 0.731 & 0.831 & 0.831 \\
\hline 2012 & 0.413 & 0.813 & 0.713 & 0.893 & 0.413 & 0.893 & 0.756 & 0.813 & 0.713 \\
\hline 2013 & 0.646 & 0.846 & 0.846 & 0.846 & 0.646 & 0.846 & 0.846 & 0.846 & 0.846 \\
\hline
\end{tabular}

From table 1 and table2, you can see that nine regional economic order degree of order degree of order parameter and economic subsystem are on the rise, these regional economic development level, economic structure, economic level is in constant development in the direction of the ordering. Per capita GDP and the whole society fixed assets as a measure of effective index of regional economic development level, degree of order tends to rise steadily, but low degree of order of investment in fixed assets in nine provinces. Local government investment and financing mode should be innovation, extensively absorb abundant folk idle capital and transportation and other large infrastructure construction, make full use of the Asian infrastructure investment Banks and fund of "silk road" to provide financial support, promote the diversification of investment, improve the efficiency in investment, Orderly degree distribution of industrial structure. The economy is driven by the second industry, the third industry development is relatively backward, and agriculture still has larger proportion, the proportion of industrial structure unreasonable problems. The "new silk road economic belt" along the region can take advantage of the long history culture and unique humanistic natural landscape to develop the tourism industry, service industry such as the third industry, in order to achieve the purpose of optimizing the industrial structure. Economic benefits, financial income and the degree of order rising steadily income, shows that the regional economic development situation is good, the production and living conditions continue to improve urban and rural residents.

3. Coordination degree of compound system. Data in Table-3 shows nine provincial economic coordination degree of compound system, southwest of the northwest five provinces and four provincial economic complex system coordination degrees.

Table 3 nine provincial economic coordination degree of compound system

\begin{tabular}{|c|c|c|c|c|c|c|c|c|c|c|}
\hline 2003 & 2004 & 2005 & 2006 & 2007 & 2008 & 2009 & 2010 & 2011 & 2012 & 2013 \\
\hline 0.021 & 0.034 & 0.036 & 0.044 & 0.06 & 0.084 & 0.068 & 0.097 & 0.136 & 0.04 & 0.134 \\
\hline
\end{tabular}

As shown in table 4, 2003-2013 "new silk road economic belt" maximum economic system coordination degree is 0.140 , the minimum value of 0.021 , with a mean of 0.095 , shows that on the whole, "the new silk road economic belt" compound system of coordinated development degree is not high. Although the vast inland regions, rich in resources, but limited by institutional constraints, weak economic foundation. In 2000 the implementation of the western development strategy for the engine of economic development in the west and promote the coordinated development of western economy. Nine provinces in western economic coordination degree decline trend in 2009 , this is due to the financial crisis of 2008 has a huge impact on our economy, our country in 2009 to stave off recession and the implementation of the four trillion plan, the investment in infrastructure such as transportation, health care, with investment stimulus pull the nine provinces of the western economic 
development. So the "new silk road economic belt" as the deepening of the western development strategy, will greatly promote the coordinated development of nine provinces in western economic. And the establishment of the fund of the Silk Road and the investment bank for the construction of the new Silk Road economic belt provides financial support.

Table 4 northwest five provinces and southwest four provincial economic coordination degree of compound system

\begin{tabular}{|c|c|c|c|c|c|c|c|c|c|c|c|}
\hline years & 2003 & 2004 & 2005 & 2006 & 2007 & 2008 & 2009 & 2010 & 2011 & 2012 & 2013 \\
\hline northwest five regions & 0.023 & 0.034 & 0.034 & 0.047 & 0.069 & 0.083 & 0.068 & 0.064 & 0.1 & 0.141 & 0.138 \\
\hline southwest four regions & 0.02 & 0.036 & 0.04 & 0.036 & 0.062 & 0.086 & 0.073 & 0.093 & 0.014 & 0.138 & 0.103 \\
\hline
\end{tabular}

Table 4 shows that the northwest five provinces of economic complex system coordination degree from 2003-2012 to stabilize rising stage with the peak in 2012, though positive, but start to decline. this is because although the northwest five provinces of economic degree of order in 2012-2013 at the rising stage, but the Shaanxi and Ningxia ordered degree of economic growth is slowing, Gansu and Xinjiang ordered degree of economic growth is stable, but the increase is not enough to offset, Shaanxi and Ningxia have slowed, Qinghai degree of order remain unchanged, so the five northwestern provinces composite economic system coordination degree reduced.

\section{Conclusions}

Through the empirical analysis result, the "new silk road economic belt" domestic degree of order of the period of economic subsystem of nine provinces along the smooth rise, laid a solid foundation for regional economic coordinated development. At present, China's economic growth is slowing, but in the western region economy maintained rapid growth, optimize industrial structure, urbanization process accelerated, has the huge advantage backwardness, is expected to become new economic growth point, reflecting the "new silk road economic belt" a major strategy is constantly release energy. According to above analysis, we suggest to emancipating the mind, strengthen cooperation and open consciousness; Set up across the administrative areas of system and mechanism construction; providing funds and improve technology conditions.

\section{Acknowledgements}

This work was supported by University Planning Funds for "New Silk Road Economic Belt" by Northwest University for Nationalities (Grant XSCZL201602) and by National Social Science Foundation of China (Grant No.12BJL072).

\section{References}

[1] Li Peng, the coordinated development of regional economy and its theoretical basis and implementation, Geography and Geographic Information Science. 4(2005) 51-55.

[2] Liu Yingji, China's regional economic coordinated development mechanism, problems and countermeasures, The Economic Aspect. 7(2012) 129-129.

[3] [Lilin, becky drive mechanism analysis of the coordinated development of regional economy, the study of contemporary economic. 5(2015) 73-73.

[4] Xiong-feng, the grey correlation analysis of the coordinated development of urban construction and economic system and modeling, Science and Technology Management Research. 10(2005)43-45.

[5] Wei Jian, the regional industry's competitiveness evaluation and path selection-north China pharmaceutical industry, Social Science Front. 5(2015)262-262. 
[6] Lilin, Wu Shan the level of regional economy coordination development in China based on DEA dynamic evaluation and comparison, China Economic Management. 9(2014) 69-71.

[7] Peng Geng, the Wuling mountain area of evaluation research of regional economy coordination, The Economic Geography. 10(2014) 39-46.

[8] Qing-song meng, complex system coordination degree model, Journal of Tianjin University 7(2000)446-446. 